\title{
An improved Bacillus subtilis cell factory for producing scyllo-inositol, a promising therapeutic agent for Alzheimer's disease
}

\author{
Kosei Tanaka', Shintaro Tajima², Shinji Takenaka ${ }^{1,2}$ and Ken-ichi Yoshida ${ }^{1,2^{*}}$
}

\begin{abstract}
Background: Bacillus subtilis 168 possesses an efficient pathway to metabolize some of the stereoisomers of inositol, including myo-inositol (MI) and scyllo-inositol (SI). Previously we reported a prototype of a B. subtilis cell factory with modified inositol metabolism that converts MI into SI in the culture medium. However, it wasted half of initial 1.0\% (w/v) MI, and the conversion was limited to produce only $0.4 \%(\mathrm{w} / \mathrm{V})$ SI. To achieve a more efficient SI production, we attempted additional modifications.
\end{abstract}

Results: All "useless" genes involved in MI and SI metabolism were deleted. Although no elevation in SI production was observed in the deletion strain, it did result in no wastage of Ml anymore. Thus additionally, overexpression of the key enzymes, IolG and IolW, was appended to demonstrate that simultaneous overexpression of them enabled complete conversion of all Ml into SI.

Conclusions: The B. subtilis cell factory was improved to yield an SI production rate of $10 \mathrm{~g} / \mathrm{L} / 48 \mathrm{~h}$ at least. The improved conversion was achieved only in the presence of enriched nutrition in the form of $2 \%(\mathrm{w} / \mathrm{v})$ Bacto soytone in the medium, which may be due to the increasing demand for regeneration of cofactors.

Keywords: Bacillus subtilis, scyllo-inositol, myo-inositol, Bioconversion, Alzheimer's disease

\section{Background}

Among the 9 inositol (1,2,3,4,5,6-cyclohexanehexol) stereoisomers, myo-inositol (MI) is the most abundant in nature (Figure 1). It serves as an indispensable structural basis for a number of secondary messengers in eukaryotic cells [1]. In contrast, the other inositol stereoisomers are relatively rare, but some are known to exert specific health-promoting effects. In particular, scyllo-inositol (SI) has been regarded as a promising therapeutic agent for Alzheimer's disease [2], one of the most common and problematic forms of dementia. Amyloid-beta (A $\beta$ ) aggregation and amyloid formation in the brain are key pathological features of Alzheimer's disease [3]. SI directly interacts with the $A \beta$ peptide and blocks the development of its fibrous aggregation [4]. In fact, oral administration of SI to a mouse model of Alzheimer's disease inhibited

\footnotetext{
* Correspondence: kenyoshi@kobe-u.ac.jp

'Organization of Advanced Science and Technology, Kobe University, 1-1 Rokkodai, Nada, Kobe 657 8501, Japan

${ }^{2}$ Department of Agrobioscience, Graduate School of Agricultural Science, Kobe University, 1-1 Rokkodai, Kobe, Nada 657 8501, Japan
}

$\mathrm{A} \beta$ aggregation, attenuated $\mathrm{A} \beta$-induced impairments of spatial memory, reduced cerebral $A \beta$ pathology, and decreased the rate of mortality [2]. Therefore, SI has received a fast-track designation from the US Food and Drug Administration for treatment of mild to moderate Alzheimer's disease.

Bacillus subtilis is one of the best-studied Gram-positive bacteria and has the ability to metabolize at least three inositol stereoisomers including MI, SI, and D-chiro-inositol (Figure 1) [5]. The B. subtilis iolABCDEFGHIJ operon encodes enzymes involved in multiple steps of inositol metabolism, and transcription of the operon is regulated by the IolR transcriptional repressor, whose gene is located immediately upstream of the operon with divergent orientation [6]. In the first step, MI is converted to scyllo-inosose by the MI dehydrogenase IolG, with $\mathrm{NAD}^{+}$reduction. IolG also dehydrogenates $\mathrm{D}$-chiroinositol to 1-keto-D-chiro-inositol, which is subsequently isomerized by Ioll to scyllo-inosose [7]. In the second step, scyllo-inosose is dehydrated by IolE to 3D-(3,5/4)trihydroxycyclohexane-1,2-dione [8]. This intermediate 


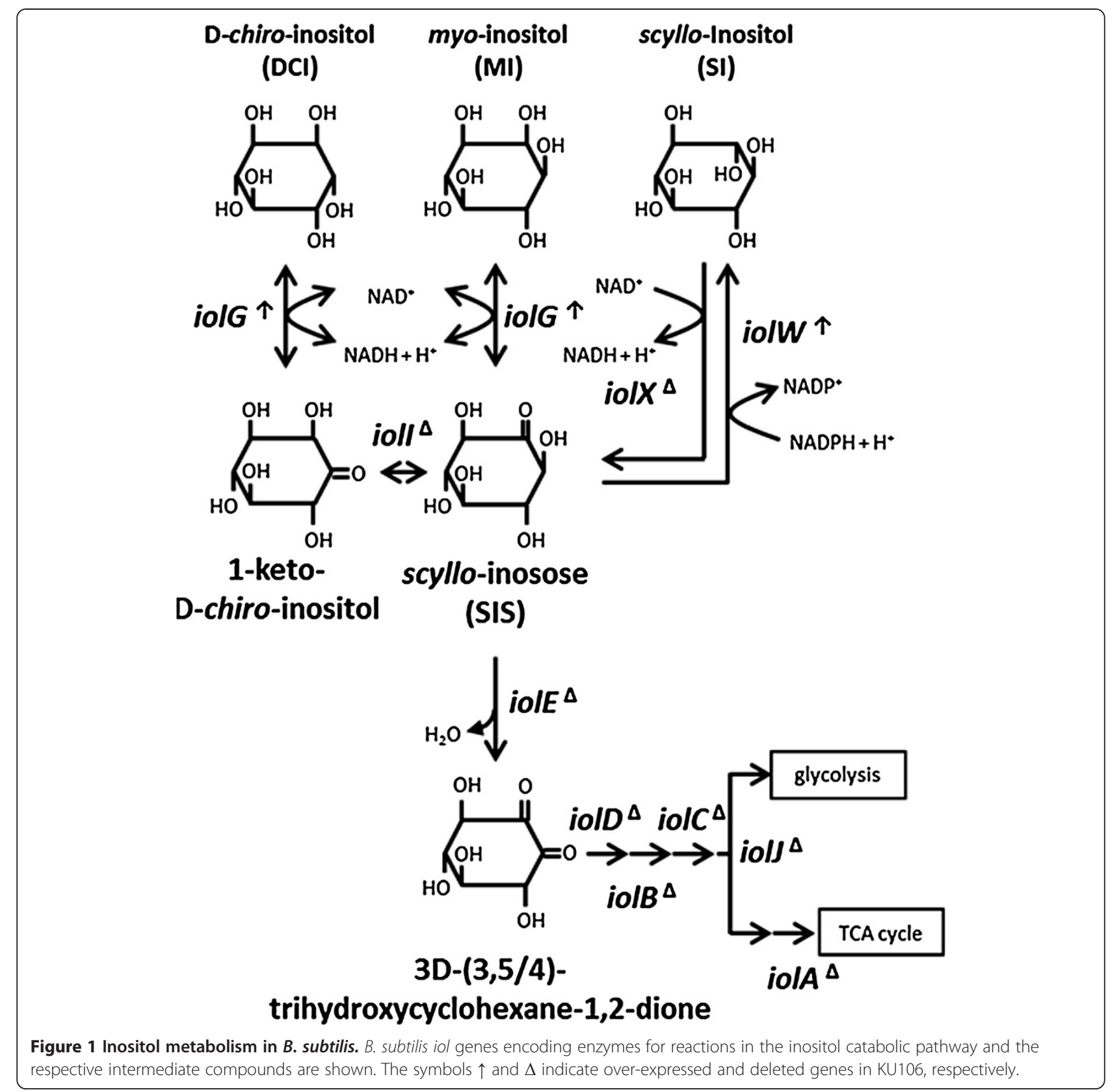

is metabolized sequentially by IolD, IolB, IolC, IolJ, and IolA, resulting in intermediates that enter glycolysis and the TCA cycle as dihydroxyacetone phosphate and acetyl-CoA, respectively [9].

B. subtilis possesses two additional and distinct inositol dehydrogenases, IolX and IolW, which act specifically on $\mathrm{SI}$ with $\mathrm{NAD}^{+}$and $\mathrm{NADP}^{+}$reduction, respectively [10]. Each of these enzymes can convert SI to scyllo-inosose, and scyllo-inosose is readily degraded further via the metabolic pathway described above [10]. Inactivation of iolX severely impairs cell growth depending on SI as the carbon source, whereas inactivation of iolW does not alter cell growth at all [10]. These results suggest that
IolX can play the major physiological role in SI catabolism, whereas IolW may function through other mechanisms, such as reduction of scyllo-inosose into SI with oxidization of NADPH, as demonstrated in vitro [10].

In a previous study, we modified the metabolism of inositol to construct strains that could convert MI into SI. Strain TM039, a prototype of a cell factory, achieved the maximum rate to convert nearly half of initial MI into SI after $72 \mathrm{~h}$ of cultivation [5]. In this strain, three genes, including iolR, iol $X$, and iolI, were disrupted and a missense mutation iolE41 was introduced. Those modifications were designed to enable constitutive expression of the iolABCDEFGHIJ operon, including iolG, and to 
disable dehydrogenation of SI as well as isomerization and dehydration of scyllo-inosose. Thus, MI was readily dehydrogenated to scyllo-inosose, which was accumulated and converted into SI by IolW, with the resulting SI appearing in the medium. However, this strain was found to consume and waste almost half of the MI initially contained in the medium [5].

In this study, we eliminated not only iolE but also all the other iol genes required for the latter steps in the metabolic pathway. We then overexpressed the two key enzymes for the conversion, IolG and IolW, to increase the conversion efficiency.

\section{Results and discussion}

\section{Deletion of iol genes irrelevant to the conversion of MI} into SI

Strain TM039, the prototype B. subtilis cell factory for producing SI, is able to convert MI into SI [5]. However, it appeared to waste half of the MI in the medium, given that only $0.4 \%(\mathrm{w} / \mathrm{v})$ SI remained after the conversion from the initial $1.0 \%(\mathrm{w} / \mathrm{v})$ MI (Table 1). We speculated that this loss was due to the residual activity of scylloinosose dehydratase encoded by iolE41 [8]. Because the iolE41 allele could not support growth on MI as a sole carbon source, we supposed that the IolE41 enzyme was severely impaired. However, it was still possible that the remaining limited activity of the mutated enzyme was involved in the wastage of MI. With the aim of eliminating the possibility, not only iolE but also iolABCDFHIJ, iol $X$, and iolR were deleted from the chromosome using a marker-free deletion technique [11] to yield strain MYI04. As expected, MYI04 did not waste MI after $48 \mathrm{~h}$ of cultivation (Table 1), although the deletion did not elevate the concentration of SI. We then speculated that the limited conversion of MI into SI resulted not from MI wastage but from the limited conversion capacity.

Table $1 \mathrm{MI}$ and SI contained in the culture media after bioconversion

\begin{tabular}{lll}
\hline Strain & MI concentration $[\%(w / v)]^{\mathbf{a}}$ & SI concentration $[\%(w / v)]^{\mathbf{a}}$ \\
\hline TM039 & ND $^{\mathrm{b}}$ & 0.40 \\
MY104 & 0.59 & 0.41 \\
KU101 & 0.53 & 0.47 \\
KU102 & 0.56 & 0.44 \\
KU104 & ND $^{\mathrm{b}}$ & 0.74 \\
& $\left(\mathrm{ND}{ }^{\mathrm{b}, \mathrm{c}}\right)$ & $\left(0.85^{\mathrm{c}}\right)$ \\
KU105 & 0.13 & 0.80 \\
KU106 & $\mathrm{ND}^{\mathrm{b}}$ & 1.00 \\
\hline
\end{tabular}

${ }^{\mathrm{a}}$ The medium initially contained $1.0 \%(\mathrm{w} / \mathrm{v}) \mathrm{Ml}$. After $48 \mathrm{~h}$ of bioconversion, concentrations of $\mathrm{MI}$ and $\mathrm{SI}$ were determined as described in the text. Values are representative data from 3 independent measurements with similar results. ${ }^{\mathrm{b}} \mathrm{ND}$, not detected $(<0.001 \%)$.

${ }^{\mathrm{c} C o n c e n t r a t i o n s ~ o f ~} \mathrm{MI}$ and $\mathrm{SI}$ at $24 \mathrm{~h}$ of bioconversion.

\section{Overexpression of iolG and iolW}

In addition to the above-mentioned deletion, we next attempted to overexpress the two genes for the key enzymes IolG and IolW with the aim of enhancing the two reactions involved in the conversion (Figure 1).

Global transcriptome analysis of B. subtilis grown under 104 different growth conditions allowed us to evaluate the strength and functional conditions of 2935 transcriptional promoters identified or predicted to date [12]. Among this large number of promoters, we chose two promoters of rpsO and rpoB, referred to as $\operatorname{Prps} O$ and PrpoB, respectively, for overexpression of iolG, judging them to be the strongest and constitutively active even during stationary growth (Figure 2B). Strains KU101 and KU102 were thus constructed, in which iolG was integrated into the $a m y E$ locus and expressed under the control of PrpsO and PrpoB (PrpsO-iolG and PrpoB-iolG, respectively). Both strains exhibited conversion rates almost equal to that of MYI04 (Table 1), indicating that increasing expression of iolG alone was not sufficient to improve the conversion.

Next, overexpression of iolW was tested similarly. Overexpression of iol $W$ markedly elevated the conversion of MI into SI; concentrations of SI reached up to $0.85 \%(\mathrm{w} / \mathrm{v})$ at $24 \mathrm{~h}$ in strain KU104 (PrpsO-iolW) and $0.80 \%(\mathrm{w} / \mathrm{v})$ at $48 \mathrm{~h}$ in KU105 (PrpoB-iolW) cultures (Table 1 and Figure 3A). These results suggested that intracellular levels of the IolW enzyme could be one of the important determinants in the conversion of MI into SI and also that $\operatorname{Prps} O$ performed slightly better than $\operatorname{PrpoB}$ in overexpressing iolW. However, even the increased supply of IolW enzyme did not result in the conversion of all MI into SI. Accordingly, the additional strain KU106, which simultaneously overexpressed iolG and $i o l W$ under the control of $\operatorname{Prps} O$, was constructed. KU106 achieved the ultimate conversion to yield 1.0\% (w/v) $\mathrm{SI}$, equal to the initial concentration of MI (Figure 3B), representing the best SI production rate of $10 \mathrm{~g} / \mathrm{L} / 48 \mathrm{~h}$ at least. These results indicate that the synchronized acceleration of the two reactions enabled by excess IolG and IolW was required for the ultimate conversion.

\section{Culture conditions enabling efficient conversion}

In a previous study, when the major nutrient, $2 \%(\mathrm{w} / \mathrm{v})$ Bacto soytone, contained in the conversion medium was reduced by half, no severe effect on cell growth was observed, whereas SI production was impaired significantly [5]. We conducted a similar test on the conversion performed by KU106. As shown in Figure 3B, when the amount of Bacto soytone in the medium was reduced by one half and one quarter, SI production was reduced to $0.72 \%(\mathrm{w} / \mathrm{v})$ and $0.52 \%(\mathrm{w} / \mathrm{v})$, respectively. Given that the two reactions in the conversion catalyzed by IolG and IolW require reduction and oxidation of the cofactors 
A

(I)

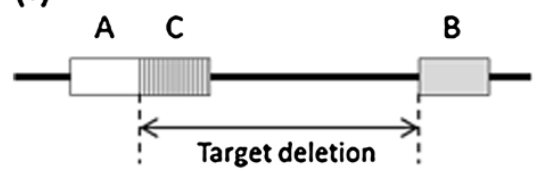

(II)

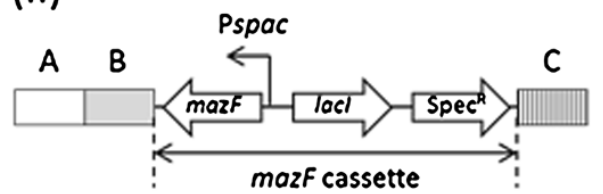

(III)

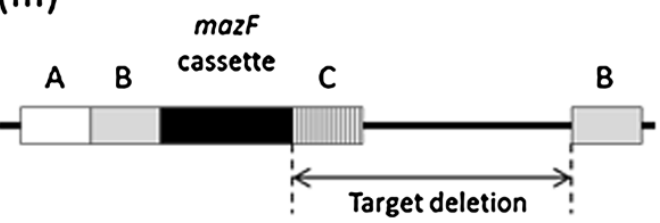

(IV)

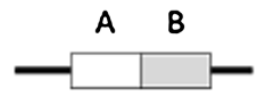

B

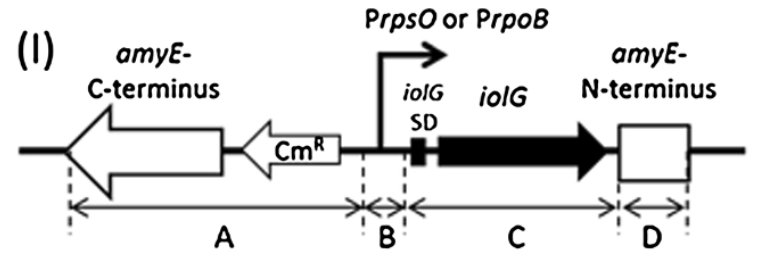

(II)

PrpsO or PrpoB

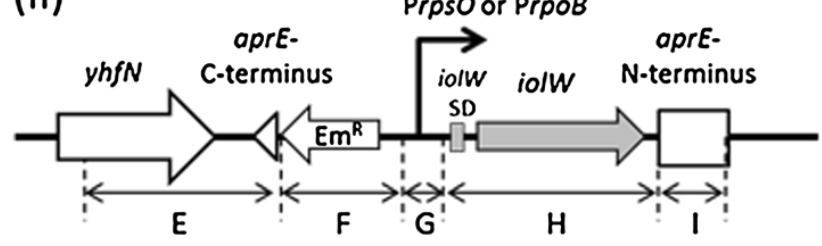

(III) PrpsO

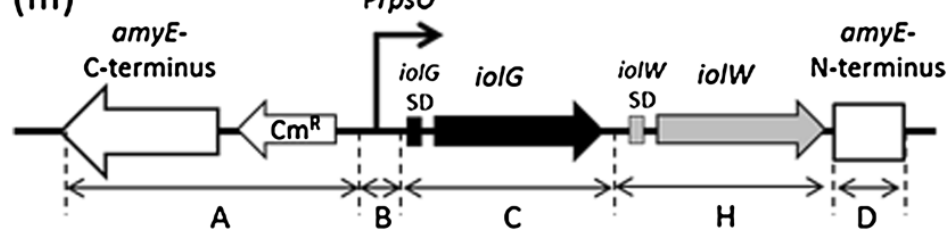

Figure 2 Construction of marker-free deletion mutants and overexpression strains of iolG and iolW. (A) Outline of the method for construction of marker-free deletion mutants. (A-I) Positional relationship between target deletion and regions $A, B$, and C contained in the PCR fragments used for construction of a marker-free deletion. A: upstream sequence; $B$ : downstream sequence; $C$ : sequence for integration of the mazF cassette. (A-II) Recombinant PCR product using fragments A, B, C, and the mazF cassette. (A-III) Integrant of the mazF cassette at the target region via a double crossover at regions $A$ and $C$. An intrachromosomal single crossover event between the 2 directly repeated regions $B$ results in elimination of the mazF cassette as well as the target region. (A-IV) Final structure of marker-free deletion. (B) Organization of the io/G and io/W overexpression cassettes. (B-I) For iolG overexpression, PCR fragments covering regions $A+B$ (containing Prps $O$ or PrpoB) $+C+D$ were ligated by recombinant PCR and integrated into the amyE locus by a double crossover event. (B-II) For io/W overexpression, PCR fragments covering regions $\mathrm{E}+\mathrm{F}+\mathrm{G}(\operatorname{Prps} \mathrm{O}$ or $\operatorname{PrpoB})+\mathrm{H}+$ I were ligated and integrated into the aprE locus for construction of an io/W-overexpressing strain. (B-III) For simultaneous overexpression of $i o / G$ and $i o / W$, a PCR fragment covering regions $A+B+C+H+D$ was ligated and integrated into the amyE locus. 


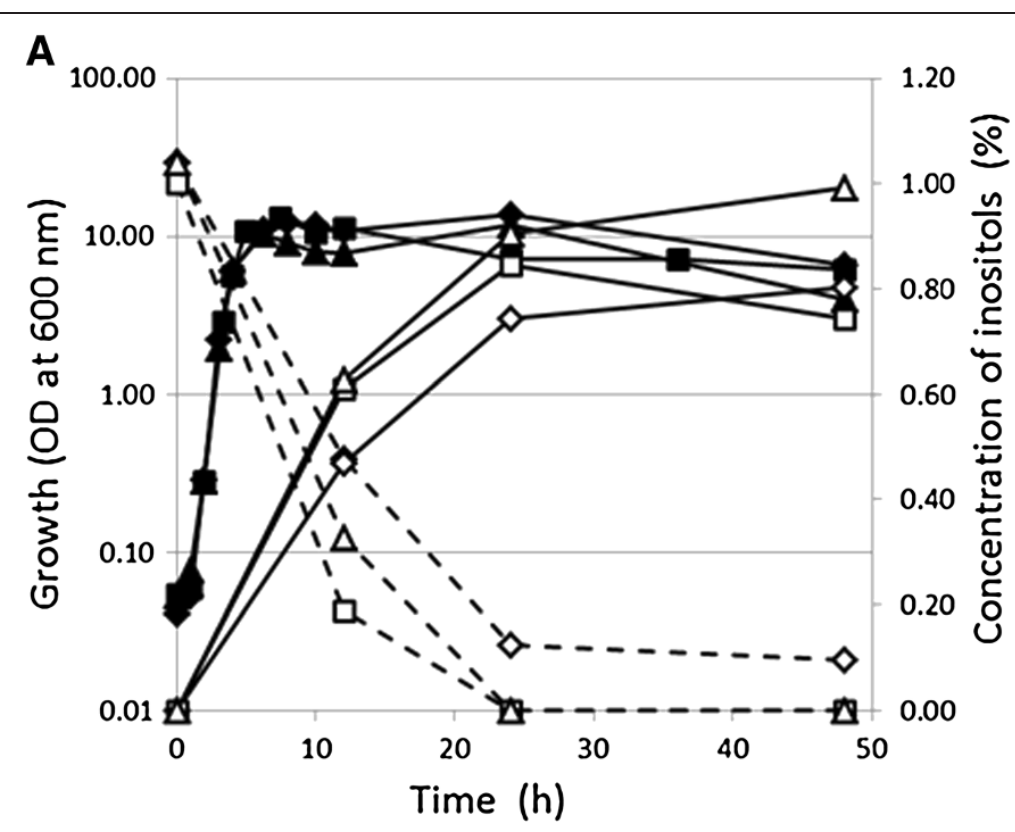

B

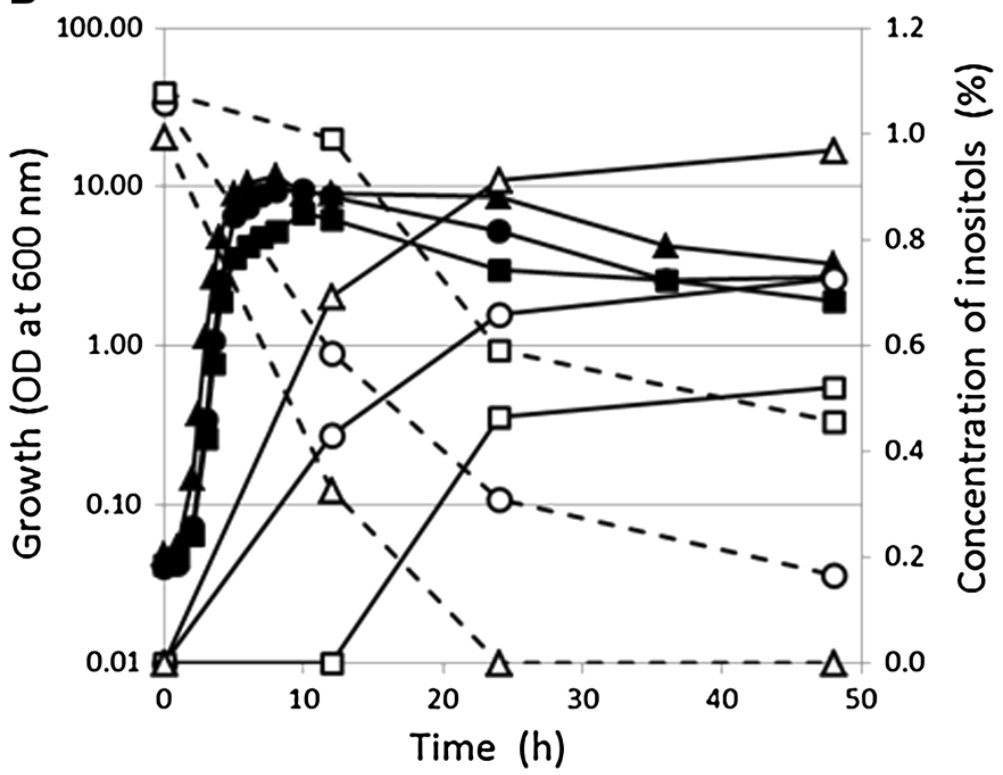

Figure 3 Time course of SI production and MI consumption along with cell growth. (A) Bioconversion from MI into SI was performed by strains KU104 (PrpsO-io/W; squares), KU105 (PrpoB-io/W; diamonds), and KU106 (PrpsO-io/G io/W; triangles). Cell growth (optical density of cells: closed symbols) and concentrations of MI (open symbols with dotted lines) and SI (open symbols with continuous lines) in the medium are shown. (B) Bioconversion of MI into SI was performed by strain KU106 (PrpsO-io/G io/M) in the presence of various concentrations of Bacto soytone; 2\% (w/v) (triangles), 1\% (circles), and 0.5\% (squares). Cell growth (optical density of cells: closed symbols) and concentrations of MI (open symbols with dotted lines) and SI (open symbols with continuous lines) in the medium are shown. A representative set of data from three independent experiments with similar results is shown.

$\mathrm{NAD}^{+}$and NADPH, respectively (Figure 1), the results suggest that higher concentrations of Bacto soytone might be involved in the regeneration of $\mathrm{NAD}^{+}$and NADPH. Assuming there could be some mechanism for cofactor regeneration, we are currently conducting an intensive investigation.
B. subtilis possesses two distinct inositol transporters, IolT and IolF, which differ in substrate specificity to MI and D-chiro-inositol $[13,14]$. In this study, we deleted iolF to construct MYI04, and the results indicated that iolF does not influence SI production and that iolT alone was enough for the ultimate conversion. However, we 
are still unable to explain how SI was secreted into the growth medium and thus, plan to identify the as-yet unknown efflux pump.

\section{Conclusions}

We have described the second generation of a B. subtilis cell factory that permits SI production at a rate of $10 \mathrm{~g} / \mathrm{L} / 48 \mathrm{~h}$ at least. The cell factory contains multiple deletions of many iol genes and simultaneous overexpression of iolG and iol $W$ for the key reactions, enabling efficient conversion of MI to SI. The highest conversion efficiency was achieved only in the presence of enriched nutrition in the form of $2 \%(\mathrm{w} / \mathrm{v})$ Bacto soytone in the medium.

\section{Methods}

\section{Bacterial strains, culture conditions, and primers}

Bacterial strains and oligonucleotide primers used in this study are listed in Tables 2 and 3, respectively. Bacterial strains were maintained in Luria-Bertani (LB) medium [15]. Antibiotics, including $0.5 \mu \mathrm{g} / \mathrm{mL}$ erythromycin, $100 \mu \mathrm{g} / \mathrm{mL}$ spectinomycin, and $5 \mu \mathrm{g} / \mathrm{mL}$ chloramphenicol, were added as required, and $1 \mathrm{mM}$ IPTG was also added to the selection medium when needed. To perform the inositol bioconversion, $100 \mathrm{~mL}$ of bioconversion medium, consisting of $2 \%(\mathrm{w} / \mathrm{v})$ Bacto soytone (Becton, Dickinson and Co., Sparks, MD), 0.5\% (w/v) Bacto yeast extract (Becton, Dickinson and Co.), 0.2\% $(\mathrm{w} / \mathrm{v})$ glucose, and $1 \%(\mathrm{w} / \mathrm{v}) \mathrm{MI}$, was added to a $500-\mathrm{mL}$ flask with baffles, inoculated with strains of B. subtilis at an optical density of 0.05 at $600 \mathrm{~nm}$, and incubated at $37^{\circ} \mathrm{C}$ with shaking at $200 \mathrm{rpm}$.

\section{Mutant construction}

MYI04 ( $\triangle$ iolR, $\triangle$ iolABCDEF, $\triangle$ iolHIJ, $\triangle i o l X)$ was constructed by employing the marker-free deletion technique [11]. First, approximately 500-bp fragments located upstream (region A as indicated in Figure 2A-I) and downstream (region B) of the target deletion were amplified by PCR. Next, an additional fragment (region C)

Table 2 Bacterial strains used in this study

\begin{tabular}{lll}
\hline Strain & Relevant genotype & $\begin{array}{l}\text { Source or } \\
\text { reference }\end{array}$ \\
\hline 168 & trpC2 & $\begin{array}{l}\text { Laboratory } \\
\text { stock }\end{array}$ \\
TM039 & iolE41 metC7 iolR::cat ioll::spc iolX::pMutin4(erm) & {$[5]$} \\
MYI04 & DiolABCDEF $\Delta$ iolHIJ $\Delta$ iolX $\Delta$ iolR & This study \\
KU101 & amyE:: PrpsO-io/G (cat) (MYI04 background) & This study \\
KU102 & amyE:: PrpoB-io/G (cat) (MYI04 background) & This study \\
KU104 & aprE:: PrpsO-io/W (erm) (MYI04 background) & This study \\
KU105 & aprE:: PrpoB-io/W (erm) (MYI04 background) & This study \\
KU106 & amyE:: PrpsO-io/G-io/W (cat) (MYl04 background) & This study \\
\hline
\end{tabular}

located immediately downstream of fragment A was amplified. These three fragments and the mazF cassette, consisting of $m a z F$ for suicidal toxin under the control of IPTG-inducible promoter (Pspac), lacI for Lac repressor controlling Pspac, and the spectinomycin resistance gene, were ligated by recombinant PCR to generate a long fragment containing the stretches corresponding to the regions $\mathrm{A}, \mathrm{B}$, the $m a z F$ cassette, and $\mathrm{C}$ in that order, as shown in Figure 2A-II. The recombinant PCR long fragments were used to transform the parental B. subtilis strain to be spectinomycin resistant via a double crossover in the homologous regions $\mathrm{A}$ and $\mathrm{C}$, and thus the $\operatorname{mazF}$ cassette was introduced into the targeted region (Figure 2A-III). The spectinomycin-resistant transformants were then screened on IPTG-containing plates for detection of spectinomycinsensitive mutants. In such mutants, an intrachromosomal single crossover event between the two direct repeat stretches corresponding to region $\mathrm{B}$ occurred to eliminate the $m a z F$ cassette and resulted in marker-free deletion between regions $\mathrm{A}$ and $\mathrm{B}$ (Figure $2 \mathrm{~A}-\mathrm{IV}$ ). To construct iolR deletion, fragments of regions $\mathrm{A}, \mathrm{B}$, and $\mathrm{C}$ were amplified using iolR-A-F/iolR-A-R, iolR-B-F/iolR-B-R, and iolR-C-F/ iolR-C-R primer pairs (Table 3), respectively. For iolABC$D E F$ deletion, the primer pairs iolAF-A-F/iolAF-A-R, iolAF-B-F/iolAF-B-R, and iolAF-C-F/iolAF-C-R, respectively, were used. Similarly, for iolHIJ deletion, iolHIJ-A-F/ iolHIJ-A-R, iolHIJ-B-F/iolHIJ-B-R, and iolHIJ-C-F/iolHIJ$\mathrm{C}-\mathrm{R}$, respectively, were used, whereas for iolX deletion, iolX-A-F/iolX-A-R, iolX-B-F/iolX-B-R, and iolX-C-F/iolX$\mathrm{C}-\mathrm{R}$, respectively, were used.

Strains KU104 and KU105 overexpressing iolG were constructed as follows. Figure 2B-I shows the schematic organization of the gene cassettes for overexpressing iolG. DNA fragments corresponding to regions $\mathrm{A}, \mathrm{B}, \mathrm{C}$, and $\mathrm{D}$ were the elements of the cassette prepared by PCR. The DNA fragment for region A was amplified from the pCRE-test plasmid [16] by PCR using the primer pair amyE-1-F/amyE-1-R, and those for regions $C$ and $\mathrm{D}$ were amplified from the chromosomal DNA of strain 168 using the pairs iolG-F/iolG-R2 and amyE-2-F/ amyE-2-R, respectively. For region $B$, two distinct fragments containing $\operatorname{Prps} O$ and $\operatorname{PrpoB}$ (referred to as $\mathrm{B} 1$ and B2, respectively) were amplified from 168 DNA by PCR using PrpsO-iolG-F/PrpsO-iolG-R and PrpoB-iolG-F/ PrpoB-iolG-R, respectively. Two sets of the four fragments, covering the regions $\mathrm{A}+\mathrm{B} 1+\mathrm{C}+\mathrm{D}$ and $\mathrm{A}+\mathrm{B} 2+$ $C+D$, were ligated by recombinant PCR using the outside primers amyE-1-F and amyE-2-R. Each of the resulting two recombinant $\mathrm{PCR}$ products possessed iolG under the control of $\operatorname{PrpsO}$ or PrpoB flanked by $\mathrm{N}$-terminal and Cterminal regions of $a m y E$ gene at either end (Figure 2B-I). Strain MYI04 was transformed to be chloramphenicol resistant by a double crossover recombination at the $a m y E$ locus to yield KU101 and KU102 as described [16]. 
Table 3 Oligonucleotide primers used in this study

\begin{tabular}{|c|c|}
\hline Name & Sequence $\left(5^{\prime} \rightarrow 3^{\prime}\right)$ \\
\hline iolR-A-F & TGCGCTGCGTAATCAATATC \\
\hline iolR-A-R & GGCTITGTTGATATTGTACTTATAAAAAACTCCTTCTTGAAT \\
\hline iolR-B-F & ATTCAAGAAGGAGTTIITTATAAGTACAATATCAACAAAGCC \\
\hline iolR-B-R & GCTTGAGTCAATTCCGCTGTCGTTGAATTCACGCAGCACTTC \\
\hline iolR-C-F & $\begin{array}{l}\text { ATTAACGTACTGATTGGGTAGGATCCGCGCTGATGCGGATTC } \\
\text { AGGAAAT }\end{array}$ \\
\hline iolR-C-R & AAGGAGCGGGTTITTCTCTT \\
\hline iolAF-A-F & GGCCAGATGAATGCCGATTT \\
\hline iolAF-A-R & ACGCCAATACGTAAACTCATTCTTATTGCCTCCTTCATTA \\
\hline iolAF-B-F & TAATGAAGGAGGCAATAAGAATGAGTTTACGTATTGGCGT \\
\hline iolAF-B-R & GCTTGAGTCAATTCCGCTGTCGGCGTGTCGACTACAGCCATA \\
\hline iolAF-C-F & $\begin{array}{l}\text { ATTAACGTACTGATTGGGTAGGATCCGCGTCAGGATGTTGAA } \\
\text { GGGGAAG }\end{array}$ \\
\hline iolAF-C-R & AGTTTGCCAAGCGTCACTTT \\
\hline iolHIJ-A-F & CATGAAATTGACGTGCTCCA \\
\hline iolHIJ-A-R & CTCGGCGGTTTCTGGTCTCTITAGTITTGAACTGTTGTAA \\
\hline iolHIJ-B-F & TTACAACAGTTCAAAACTAAAGAGACCAGAAACCGCCGAG \\
\hline iolHIJ-B-R & GCTTGAGTCAATTCCGCTGTCGAAACGCAGTTCAAACCGTTC \\
\hline iolHIJ-C-F & $\begin{array}{l}\text { ATTAACGTACTGATTGGGTAGGATCCGCGCGCACTCGTTITC } \\
\text { TTCAACA }\end{array}$ \\
\hline iolHIJ-C-R & AATGGCTTCCTCAGCAGTC \\
\hline iolX-A-F & GCTCCGACTGCTATTITTGC \\
\hline iolX-A-R & TAAGCGCGCTTCACATCTAGCAATACTGCACATCTTACTT \\
\hline iolX-B-F & AAGTAAGATGTGCAGTATTGCTAGATGTGAAGCGCGCTTA \\
\hline iolX-B-R & GCTTGAGTCAATTCCGCTGTCGCGGAGGAAACTGCCTATCAA \\
\hline iolX-C-F & $\begin{array}{l}\text { ATTAACGTACTGATTGGGTAGGATCCGCGGCCTTGAGGAA } \\
\text { TCAAAAGCA }\end{array}$ \\
\hline iolX-C-R & TCCGTATGGAGAGGTTCTGC \\
\hline amyE-1-F & CCTTCCAGGGTATGTTTCTC \\
\hline amyE-1-R & CAAACGAAAATTGGATAAAGTGGG \\
\hline PrpsO-iolG-F & $\begin{array}{l}\text { CCCACTTIATCCAATTTTCGTTTGATGGCATCAAAGAATTAA } \\
\text { CTGAGC }\end{array}$ \\
\hline PrpsO-iolG-R & $\begin{array}{l}\text { CCTICTITACTTGGCTCTGAGGCCAAATCATATTTAGCCCC } \\
\text { AGTTACC }\end{array}$ \\
\hline PrpoB-iolG-F & CCCACTTATCCAATTTTCGTTGGGCGCGCCTTCTGCCATTG \\
\hline PrpoB-iolG-R & $\begin{array}{l}\text { CCTITCTIACTTGGCTCTGAGGGCGTATTATATGTGTAATA } \\
\text { AGCATTTC }\end{array}$ \\
\hline iolG-F & CCTCAGAGCCAAGTAAAGAAAGG \\
\hline iolG-R2 & $\begin{array}{l}\text { CACAAATTAAAAACTGGTCTGATCGCCTCTGTTITTAGTTT } \\
\text { TGAACTGTTG }\end{array}$ \\
\hline amyE-2-F & CGATCAGACCAGTITTTAATTTGTG \\
\hline amyE-2-R & TTAACAAAATTCTCCAGTCTTCACATCG \\
\hline aprE-1-F & CAATCTITACGCTITGCGTTCTCG \\
\hline aprE-1-R & $\begin{array}{l}\text { GTTACACGTTACTAAAGGGAATGTAGCGGAGCAGCAGCG } \\
\text { TTAATTC }\end{array}$ \\
\hline Em-F & CTACATTCCCTTTAGTAACGTGTAAC \\
\hline Em-R & GAGTGTGTTGATAGTGCAGTATC \\
\hline
\end{tabular}

Table 3 Oligonucleotide primers used in this study (Continued)

\begin{tabular}{|c|c|}
\hline PrpsO-iolW-F & $\begin{array}{l}\text { GATACTGCACTATCAACACACTCATGGCATCAAAGAATTA } \\
\text { ACTGAGC }\end{array}$ \\
\hline PrpsO-iolW-R & $\begin{array}{l}\text { GTATATACCCTCCTGATCAAATGGCCA } \\
\text { AATCATATTIAGCCCCAGTTACC }\end{array}$ \\
\hline PrpoB-iolW-F & $\begin{array}{l}\text { GATACTGCACTATCAACACACTCGCGC } \\
\text { GCCTTCTGCCATTG }\end{array}$ \\
\hline PrpoB-iolW-R & $\begin{array}{l}\text { GTATATACCCTCCTGATCAAATGGGCG } \\
\text { TATTATATGTGTAATAAGCATTTC }\end{array}$ \\
\hline iolW-F & CCATTTGATCAGGAGGGTATATAC \\
\hline iolW-R & GATTGCGCGTGCGAAAGAAG \\
\hline aprE-2-F & $\begin{array}{l}\text { CTTCTITCGCACGCGCAATCCGCAAAC } \\
\text { AACAAGCTGATCCAC }\end{array}$ \\
\hline aprE-2-R & GACATTCGGCACACTCCTITTC \\
\hline iolG-R & CCTCTGTIIITAAGTITGAACTGTTG \\
\hline iolW-F-Tail & $\begin{array}{l}\text { CAACAGTTCAAAACTAAAAAACAGAGG } \\
\text { CCATTGATCAGGAGGGTATATAC }\end{array}$ \\
\hline iolW-R-Tail & $\begin{array}{l}\text { CGATGTGAAGACTGGAGAATTTGTTAA } \\
\text { GATTGCGCGTGCGAAAGAAG }\end{array}$ \\
\hline mazFK7-F & CGACAGCGGAATTGACTCAAGC \\
\hline mazFK7-R & CGCGGATCCTACCCAATCAG \\
\hline
\end{tabular}

Similarly, strains KU104 and KU105 overexpressing iol $W$ were constructed as follows. Figure 2B-II shows the gene cassette for iolW overexpression. DNA fragments for the regions $\mathrm{E}, \mathrm{F}, \mathrm{H}$, and I were amplified by PCR using the primer pairs aprE-1-F/aprE-1-R, Em-F/ Em-R, iolW-F/iolW-R, and aprE-2-F/aprE-2-R, respectively. Two fragments for regions $\mathrm{G}$ containing $\operatorname{Prps} O$ and PrpoB (referred to as G1 and G2, respectively) were amplified using PrpsO-iolW-F/PrpsO-iolW-R and PrpoB-iolWF/PrpoB-iolW-R, respectively. Two sets of the five fragments, covering the regions $\mathrm{E}+\mathrm{F}+\mathrm{G} 1+\mathrm{H}+\mathrm{I}$ and $\mathrm{E}+\mathrm{F}+$ $\mathrm{G} 2+\mathrm{H}+\mathrm{I}$, were ligated by recombinant PCR with the outside primers of aprE-1-F and aprE-2- $\mathrm{R}$ and used to transform MYI04 by a double crossover recombination at the aprE locus to obtain KU104 and KU105, respectively.

Strain KU106, simultaneously overexpressing iolG and iol $W$, was constructed as follows. DNA fragments for regions $\mathrm{A}, \mathrm{B}$, and $\mathrm{D}$ were amplified by $\mathrm{PCR}$ as described above (Figure 2B-I). Fragments for regions $\mathrm{C}$ and $\mathrm{H}$ were amplified using the primer pairs iolG-F/iolG- $\mathrm{R}$ and iolW-F-tail/iolW-R-tail, respectively (Figure $2 \mathrm{~B}-\mathrm{I}$ and II). These five fragments, covering regions $\mathrm{A}+\mathrm{B}+\mathrm{C}+\mathrm{H}+\mathrm{D}$, were ligated by recombinant PCR with outside primers of amyE-1-F and amyE-2-R. The resulting PCR product, containing iolG and iolW genes under the control of PrpsO flanked by the N-terminal and C-terminal regions of amyE, was used to transform MYI04 by a double crossover recombination at the $a m y E$ locus to obtain KU106. 


\section{Measurement of $\mathrm{MI}$ and $\mathrm{SI}$ in medium}

Bacterial culture was diluted appropriately with pure water when required, and cells were removed from the culture medium by centrifugation. The supernatant was mixed with AG $50 \mathrm{~W}-\mathrm{X} 8$ resin (Bio-Rad, Hercules, CA) for $1 \mathrm{~h}$ at $4^{\circ} \mathrm{C}$, and then passed through an Amicon Ultra- $0.5 \mathrm{ml} 3 \mathrm{~K}$ Centrifugal Filter (Millipore, Billerica, MA). The eluent was subjected to high-performance liquid chromatography (LaChrom Elite: HITACHI High Technologies, Tokyo, Japan) with refractive index detection using a Wakosil5NH2 column $(4.6 \times 250 \mathrm{~mm})$ (Wako Pure Chemical Industries, Osaka, Japan) maintained at $25^{\circ} \mathrm{C}$ with a flow of acetonitrile/water $(80 / 20)$ at $2 \mathrm{~mL} / \mathrm{min}$. The retention time was used to identify the stereoisomers, and refractive index units were used to calculate their concentrations.

\section{Abbreviations}

Ml: myo-inositol; SI: scyllo-inositol; A $\beta$ : Amyloid-beta.

\section{Competing interests}

The authors declare that they have no competing interests.

\section{Authors' contributions}

Conception and design of the study: KY. Acquisition of data: KT and STj. Analysis and interpretation of data: KT. Drafting the article: KT. Revising it critically for important intellectual content: KY and STk. Final approval of the version to be submitted: all co-authors. All authors read and approved the final manuscript.

\section{Acknowledgments}

This work was financially supported by the Ministry of Education, Culture, Sports, Science, and Technology, Japan, in part by Special Coordination Funds for Promoting Science and Technology, Creation of Innovative Centers for Advanced Interdisciplinary Research Areas; by the Advanced Low-Carbon Technology Research and Development Program; and by Grants-in-Aid from the NC-CARP project. The authors would like to thank Enago (www.enago.jp) for the English language review.

Received: 26 September 2013 Accepted: 3 December 2013

Published: 11 December 2013

\section{References}

1. Irvine RF, Schell MJ: Back in the water: the return of the inositol phosphates. Nat Rev Mol Cell Biol 2001, 2:327-338.

2. McLaurin J, Kierstead ME, Brown ME, Hawkes CA, Lambermon MH, Phinney AL, Darabie AA, Cousins JE, French JE, Lan MF, Chen F, Wong SS, Mount HT, Fraser PE, Westaway D, St George-Hyslop P: Cyclohexanehexol inhibitors of Abeta aggregation prevent and reverse Alzheimer phenotype in a mouse model. Nat Med 2006, 12:801-808

3. Geylis V, Steinitz M: Immunotherapy of Alzheimer's disease (AD): from murine models to anti-amyloid beta (Abeta) human monoclonal antibodies. Autoimmun Rev 2006, 5:33-39.

4. McLaurin J, Golomb R, Jurewicz A, Antel JP, Fraser PE: Inositol stereoisomers stabilize an oligomeric aggregate of Alzheimer amyloid beta peptide and inhibit abeta-induced toxicity. J Biol Chem 2000, 275:18495-18502.

5. Yamaoka M, Osawa S, Morinaga T, Takenaka S, Yoshida K: A cell factory of Bacillus subtilis engineered for the simple bioconversion of myo-inosito to scyllo-inositol, a potential therapeutic agent for Alzheimer's disease. Microb Cell Fact 2011, 10:69.

6. Yoshida K, Aoyama D, Ishio I, Shibayama T, Fujita Y: Organization and transcription of the myo-inositol operon, iol, of Bacillus subtilis. J Bacteriol 1997, 179:4591-4598.

7. Yoshida K, Yamaguchi M, Morinaga T, Ikeuchi M, Kinehara M, Ashida H: Genetic modification of Bacillus subtilis for production of D-chiro-inositol, an investigational drug candidate for treatment of type 2 diabetes and polycystic ovary syndrome. Appl Environ Microbiol 2006, 72:1310-1315.

8. Yoshida K, Yamaguchi M, Ikeda H, Omae K, Tsurusaki K, Fujita Y: The fifth gene of the iol operon of Bacillus subtilis, iolE, encodes 2-keto-myo-inositol dehydratase. Microbiology 2004, 150:571-580.

9. Yoshida K, Yamaguchi M, Morinaga T, Kinehara M, Ikeuchi M, Ashida H, Fujita Y: myo-Inositol catabolism in Bacillus subtilis. J Biol Chem 2008, 283:10415-10424.

10. Morinaga T, Ashida H, Yoshida K: Identification of two scyllo-inositol dehydrogenases in Bacillus subtilis. Microbiology 2010, 156:1538-1546.

11. Morimoto T, Ara K, Ozaki K, Ogasawara N: A new simple method to introduce marker-free deletions in the Bacillus subtilis genome. Genes Genet Syst 2009, 84:315-318.

12. Nicolas P, Mäder U, Dervyn E, Rochat T, Leduc A, Pigeonneau N, Bidnenko E, Marchadier E, Hoebeke M, Aymerich S, Becher D, Bisicchia P, Botella E, Delumeau O, Doherty G, Denham EL, Fogg MJ, Fromion V, Goelzer A, Hansen A, Härtig E, Harwood CR, Homuth G, Jarmer H, Jules M, Klipp E, Le Chat L, Lecointe F, Lewis $P$, Liebermeister W, et al: Condition-dependent transcriptome reveals high-level regulatory architecture in Bacillus subtilis. Science 2012, 335:1103-1106.

13. Yoshida K, Yamamoto $Y$, Omae K, Yamamoto M, Fujita Y: Identification of two myo-inositol transporter genes of Bacillus subtilis. J Bacteriol 2002, 184:983-991.

14. Morinaga T, Matsuse $T$, Ashida H, Yoshida K: Differential substrate specificity of two inositol transporters of Bacillus subtilis. Biosci Biotechnol Biochem 2010, 74:1312-1314.

15. Sambrook J, Russell DW: Molecular Cloning: A Laboratory Manual. Cold Spring Harbor Press: Cold Spring Harbor; 2001.

16. Miwa Y, Nakata A, Ogiwara A, Yamamoto M, Fujita Y: Evaluation and characterization of catabolite-responsive elements (cre) of Bacillus subtilis. Nucleic Acids Res 2000, 28:1206-1210.

doi:10.1186/1475-2859-12-124

Cite this article as: Tanaka et al:: An improved Bacillus subtilis cell factory for producing scyllo-inositol, a promising therapeutic agent for Alzheimer's disease. Microbial Cell Factories 2013 12:124.

\section{Submit your next manuscript to BioMed Central and take full advantage of:}

- Convenient online submission

- Thorough peer review

- No space constraints or color figure charges

- Immediate publication on acceptance

- Inclusion in PubMed, CAS, Scopus and Google Scholar

- Research which is freely available for redistribution 